\title{
Discussion on Gender Differences and Costume
}

\author{
Wei Yin \\ Department of Garment Designing and Engineering, Minjiang University \\ 1 Wenxian Street, University Park, Fuzhou 350108, China \\ E-mail:wei_e80@126.com
}

\begin{abstract}
Society has assigned different expectation and obligation to male and female. And this difference is shown in many ways, especially in clothing. Society prescribes standard costume for both sexes. Human clothing represents great otherness because of the gender differences. This dissertation is to discuss the relationship between gender differences and costume.
\end{abstract}

\section{Keywords: Gender differences, Costume, Reverse}

\section{Introduction}

Gender differences, are the differences between men and women. It is an eternal proposition. By these born differences as well as the innermost feelings and the sexual relations, it has certain influence to the costume art. As is said in Chinese, Yin and Yang, are two opposing principles in nature, the former feminine and negative while the latter masculine and positive. Generally speaking, women have the characteristics of softness, exquisiteness, geist and caprice, while men are often considered adamant, brave, rational and straightforward. As a result of these differences, the divisions of costume shapes are also extremely visible.

\section{Costume and consciousness of gender differences}

After being born the human form cannot help but to receive the behavior pattern the society stipulates. The expectation of culture is first realized through costume, causing him to put on the accordant clothing for his gender. Girls are in favors of soft, romantic and well-decorated clothing while boys prefer terse, spiffy, and sober clothing. If one does not get the proper psychology of sex in his childhood, he is likely to get a costume behavior that does not tally with his own sex in the growth process. If the boy displays an enormous interest to girl's clothing, he may encounter people's censure and ridicule. It is obvious that one was told everything about his gender since he was young and this kind of consciousness of sex is naturally shown by costume which is closely linked with his life.

Men's and women's gender differences are created by nature force. These natural differences have decided their behaviors. However, the human spirit voluntarily destroyed this kind of psychological structure. The gender gap the slave society constructed causes both sexes' personalities to appear enormous inclining. After the slave society, human culture enlarges this gap, from behavior manner to costume appearance, and consciously molds sexes in ideaistic differences. The silk painting of Chu Grave discovered in China, showed that over two thousands years ago, costume already has gender differences. In literature and history record, Chou Dynasty's clothing system displayed obvious sexual status. The different social position of both sexes has been performed through clothing. In the west, far in 2800BC in Mesopotamia, costume already had different manifestation by gender.

In certain societies, there is not only different anticipation to the amphoteric clothing, but also the strict taboo. Famous scholar C.Braun pointed out in "Explaining Other Cultures": "In our society, women possibly put on masculine clothing, but people absolutely oppose men putting on feminine clothing." Indeed, in most societies, if a male wears female clothing, he may receive the public's ridicule. Similarly, if a female puts on excessively virilized clothing, she will lose her gentle and beauty. It can be said that, putting on different clothing to differentiate gender, has deeply taken root in social culture and daily life. Even some countries establish this custom stipulation in the statute books, or observe this as a kind of social ethics in some area. Some also forbid acting opposite gender in the stage role.

Beauty of firmness and beauty of gentilesse, are both kinds of intrinsic beauty. The corresponding costume can display the different characteristic, by strengthening this kind of esthetic standard. Usually, the feminine costume shows sexual characteristics obviously. First, feminine costume reveals stature. For example, the Egyptian women in ancient times were putting on tight and long tunic, unfolding exquisite and exposed body. Secondly, colors displayed the female particular sexual characteristic, such as "Megranate Skirt" (a kind of red skirt dyed with madder) which was super welcomed by women in Chinese Tang Dynasty. Thirdly, the structure or the modeling is variant with that of male's, generally decorated much, divided often. The modeling outline is usually curving. From the tight-fitting corsage of 16th 
century to the tight-fitting pants of 19th century, the outline has dome shape, bell shape, ballet shape and so on. Overall the female costume style is so diverse as to make people dazzled. However the masculine costume is often showing strength, speed, innervation and personality. The outline shape is clear and succinct, with straight line primarily; The structure is vivid without much decoration; The color is steady, capable and simple.

\section{The sexual reverse in costume history}

Nature has given men and women sexes which distinguish them mutually, but not all of the people accept the roll they get. For those people, they often attenuate their role by wearing clothing. For example some quite delicate women who are not satisfied with their own characteristic, may wear the virilized clothing to attenuate their own female characters and emphasize decisive and capable individualities.

As a result of the sexual difference, female are always in the subordinate position in our society. The society's crackdown disables them to realize their own desire, thereupon melts this kind of strong desire into one kind of spiritual reposing, realizing it through costume. Hua Mulan who joined the army instead of her father in China ancient times might be an example in the costume history who dared to counterwork this kind of rule. It is indicated in ancient literature and history record that female putting on men's clothing was popular in China's Tang Dynasty. Open costume design was gloomed in Tang Dynasty's historical environment. Women liked to put on a kind of clothing which is called Hu minority's clothing. Its typical sample has brocade in the collar, sleeve with decoration, circle collar, narrow sleeve, felt hat, grass belt, small mouth trousers, and soft boots. In ancient times there were also female taking part in government in men's clothing and this was inseparable from the prevailing custom at that time.

The sex-reverse, may also be called the sexual dislocation. Men and women's relations originally should be mutually exclusive, like two weights of a balance. However, if one wears the opposite sex's attire excessively and pieces together carelessly, then this kind of funny costume behavior will not only destroy society esthetic rule but also be laughed at by people.

During China's "Great Cultural Revolution", female dare not marcel or wear skirt. Men and women all put on large green military uniform or the Chinese tunic suit or its variational clothing, merely different in the collar, the pocket and the waist. It is most absurd that Jiang Qing designed "the Jiang Qing skirt" which is appraised by people: "One half looks like male; the other half looks like female. It looks likes nun from behind and monk from front."

A renowned writer once said that, "I like woman's clothing, because they are too absurd." But too few people calmly think that, since several centuries, men's clothing is just like this. Man also has the vanity that woman has in the clothing aspect. It is because their life and women's are extremely similar. They have many serfs working for them, so these aristocrats live profligately, and accordingly their clothing is also profligate. In order to manifest their status through clothing, they enjoy the pleasure and satisfaction clothing brings by any means possible, causing men's clothing more and more exaggerated. In ancient Egypt, men used jewelry, tower-shaped hairstyle, hairpiece and cosmetics. Men of ancient Assyria liked thrush, all kinds of cosmetics, and to sprinkle diamond dust on the hair. Greek and Rome's young people also liked women's attire. Empress Elizabeth advocated frivolous fancy clothing to her royal courtier. Men put on leotard, wore earring, put on collar with lace and wore feather hat with the gem, looking just like woman without any difference. In 18th century, the English decadents established the dandy club. These aristocrat members wore long silk stockings and butterfly knot, laughable and frivolous but famous. Roman asceticism philosopher Seneca made the following narration for those men: "Among us some men would rather keep long hair, dress up themselves like a woman, causing all nations to be laughed at." "Men in female clothing cannot be forgiven. They have not any difference with women except the spinning wheel." Even fashion aristocrats of the upper ten also express their view: "I hope women not to dress up grotesquely and gentlemen not to dress up like dancing experts." But, these caustic criticism and ridicule have not weakened these playboys' dispirited attire slightly.

\section{Calling on the appropriate beauty of dislocation}

The French revolution changed the national condition, eliminated aristocrat's property, causing them not able to continue their luxurious life or to dress up like women. The middle class men chose simple style instead of magnificent style. From then on, the bright colorful faggy palace dress went into hiding, and came the modern costume which is fuscous in color, simple and steady. Men's costume trends standard very quickly, and does not have remarkable difference every year. Men in fastidious attire are no longer considered lacking esthetic performance. When the world war occurred, women were pushed towards society. The women's liberation movement deeply affects female clothing and female attire has been more and more advantageous for work. In 1970 the women's movement initiated the violent attack to the traditional natural role. They thought "the natural role" and "the natural psychology" had caused male and female unfair. Women of the entire civilized world did not pay attention to the moral scientists' attack, liberated themselves from the past despotic costume, and threw the suffocating tight-fitting corsage, the unwieldy skirt bracket, the ill-suited small shoes and so on into the garbage heap of history.

Modern civilization causes the amphoteric psychological pattern to change. One of its performances is the equality, 
which confirms female has equal value as male. The change of sexual role has led human esthetic idea to change. Strength is no longer male's unique characteristic, and at the same time it can also be seen on female body. Daintiness is not only feminine characteristic, but also male's. Esthetic sense's change can reflect inevitably on costume. This has become a phenomena of contemporary fashionable costume. In modern society, more and more women go to work, and take on the work which was always taken by men. The modern female costume obvious trends to virilization, or is designed with some virilized designs. The jeans which was created for men also become a modern feminine fashion, because the jeans shows the body sex, the vigor of youth, the exquisite line of feminine buttocks and legs. The western-style clothes, the shirt, the tie, the suspenders, the lining shoulder, the military uniform and so on, many men's clothing elements are also used by the multitudinous designers in their female costume design.

At the same time, men's costume also starts to use the female costume elements in the design, the decoration, the color, the modeling, etc. Orange color, lemon yellow, scarlet and so on are added; They also use narrow-body design and some details which are belonged to female clothing originally such as embroideries. In 1967, in US men's costume reform movement, so-called "peacock revolution" was raised. Its objective was to promote diversification of men's costume. It advocated that men's costume must manifest the spirit of the age. This leads to a great change of men's costume in color and design all over the world. The 60's "hippie", the 80's "yuppies", until the 90's "the X race", once, these vanguard styles of men's costume were described with "the effeminacy", "artificially carves" and so on, and many people regard that these clothing are feminized and sideline products of homosexuality. It sometimes makes sense, but we cannot deprive person with normal sex orientation to choose clothing. The tide cannot be explained by logic, especially in the age where individuality principle is so popular. Young boys diligently choose the same gorgeous shirt and long hair as girls, at will, freely and easily. It is fit to describe this with the American photographer Cecil Beaton's words: "He is both attractive and ugly; he is like a woman and also a man; he is very sexy, but unable to summon your libido."

In films and television plays, men's feminization has revealed the clue. The international design masters also start to put more feminization elements into men's costume. "The narrow-body design, lace material, transparent lining, embroidery and fresh colors are boldly used. Vivienne Wister Wood 's designs have boldly used the female costume designs: the chest prominent, the buttocks obvious, full of feminine qualities. The D\&G men's costume is filled with obvious feminization style and kind of playboy's dissolute breath style. The Armani men's clothing's biggest characteristic, is that the designer likes using materials similar to the female clothing such as extremely soft cloth, which gives the western-style clothing a different feeling. For the non- muscle gentleman, this kind of clothing is certainly good to decorate the effect. These have been catering to the present tide in the feminization of men's clothing, and the virilization of female costume.

In modern society many neutral clothing appear which men and women can both put on. It has only size distinction, but not the gender boundary. Its size changes to a balance point, and can match both men and women. In modern society, men and women have different characteristics and take on different social positions, but human's psychological quality does not take gender as the classified standard. Men can be engaged in the feminine work, and women can also take on the masculine post. Under this condition, people have the desire to close up to the opposite gender. People realize that different genders need supplementary. The person with characteristics of the two genders at the same time, will probably have more advantage to succeed. In other words, if a woman combines her chariness with masculine logic and courage together, she will get twice the result with half the effort in her work. Since people have such desire, they will have its external performance naturally. If they show this thought through their clothing properly, a kind of appropriate beauty of dislocation will be formed.

The progress of civilization, "gives both genders the same respect and appraisal". This is coordination of personality value, but not the sexual assimilation. The sexual characteristics and gender differences will eternally exist, for it is the need of human life. Therefore, the sex appeal of both genders' clothing, is not unification of genders. The male's and female's sex appeal which clothing displays will never vanish, and the diversities exists forever. But, seeking the similarity from the diversities, will possibly become the subject of costume design in the future.

In brief, the social culture has constructed the sex idea based on the sexual differences, formed humanity's costume standard, and combined masculine beauty and feminine beauty with their different esthetic characteristic. It is just this characteristic that has caused the different fashionable psychology in the development of costume design. Along with society's development and the gender equality, the costume standard will unceasingly change the proportion of masculine beauty and feminine beauty.

\section{References}

Anne, Hollander. (2000). Sex and Suite. Eastern Publishing House.

Liao, Weichun. (2005). Gender Fashions Finery. Shanghai Translation Publishing House. 